\title{
THE SURGERY FOR MULTIPLE-ELECTRODE COCHLEAR IMPLANTATIONS
}

BY

GRAEME M. CLARK, BRIAN C. PYMAN and QUENTIN R. BAILEY

THE JOURNAL OF LARYNGOLOGY AND OTOLOGY

Vol. XCIII No.3 March 1979 


\title{
The surgery for multiple-electrode cochlear implantations
}

\author{
By Graeme M. Clark, Brian C. Pyman and Quentin R. Bailey \\ (Melbourne)
}

\section{Introduction}

THE multiple-electrode hearing prosthesis designed in the Departments of Otolaryngology and Electrical Engineering (UMDOLEE) at the University of Melbourne (Clark et al., 1977) has been miniaturized with hybrid circuitry so that, if design changes are necessary as a result of initial patient testing, they can be made at minimal cost. This results, however, in increased package dimensions which makes its placement and the design of the surgery more critical. This problem is increased by the fact that we have considered it important to be able to remove the package and replace it with another without disturbing the implanted electrode array, should the first receiver-stimulator fail or an improved design become available. This has meant the design of a special connector (Patrick, 1977; Clark et al., 1978) which adds to the dimensions of the implanted unit. In addition the placement of the coils for transmitting power and information has to be considered. Not only is it desirable to site the coils at a convenient location behind the ear to facilitate the placement and wearing of the external transmitter, but there should also be no relative movement between the coils and the electronic package. These design considerations have led to the siting of the coils on top of the hermetically-sealed box, and further increased the height of the package.

The dimensions of the package shown in Fig. 1 are length $42 \mathrm{~mm}$, width $32 \mathrm{~mm}$, height of connector $8.5 \mathrm{~mm}$, height of receiver-stimulator unit $13 \mathrm{~mm}$. The surgical considerations discussed are the result of a number of temporal bone and cadaver dissections, and the surgical implantation at The Royal Victorian Eye and Ear Hospital of the UMDOLEE unit in a specially-selected patient.

\section{Surgical procedure}

The patient is placed on the operating table with the head horizontal and a $20^{\circ}$ foot-down tilt. After skin preparation and draping, an incision is made through the skin in the postaural sulcus from the mastoid tip to the supramastoid crest. The fascia is divided in layers and elevated to expose Henle's spine, the suprameatal triangle, post-auditory process and anterior aspect of the mastoid bone. The auditory canal skin is elevated from the 


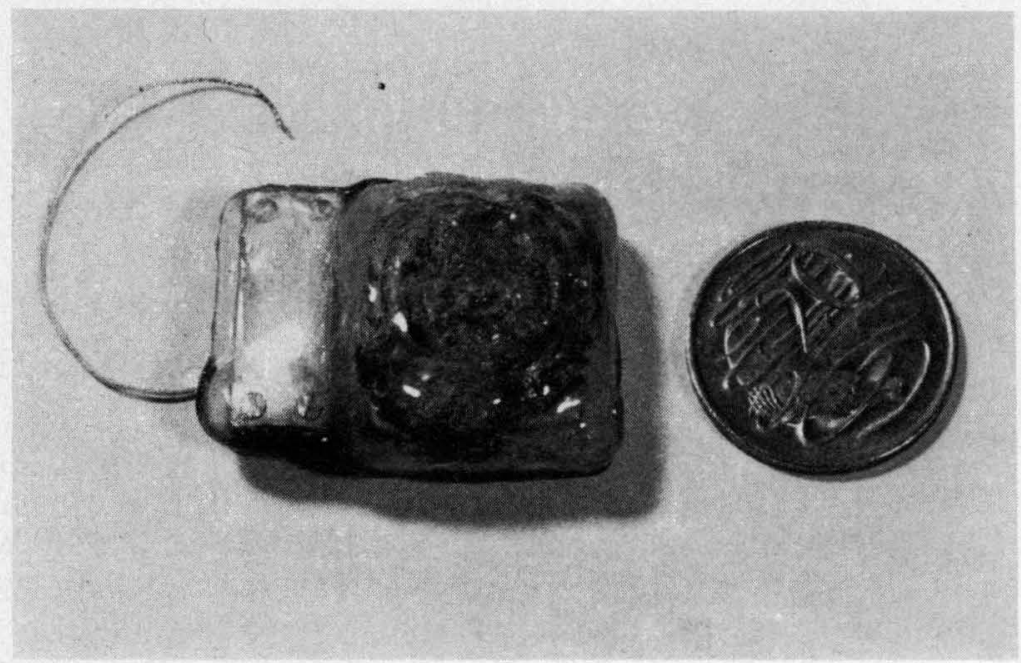

FIG. 1

A photograph of the UMDOLEE multiple-electrode prosthesis for implantation next to a 20 cent piece.

posterior wall, and from the superior wall as far as the squamo-tympanic fissure. The tympanic membrane is elevated and the middle ear inspected with particular attention to the presence of disease and the anatomy of the round window niche. The incision through the skin is then extended upwards and backwards in an arc for a distance of $5 \mathrm{~cm}$, and then downwards for $4 \mathrm{~cm}$ (Fig. 2). Care is taken to avoid acute angles at the superior corners of the flap. The skin flap is then dissected from the underlying subcutaneous and deep fascia. Following haemostasis, a superficial and deep flap of fascia are both elevated with their bases placed inferiorly (Fig. 2). The superficial flap contains some subcutaneous tissue, and the deep flap contains periosteum overlying the mastoid bone and fascia over the sterno-mastoid muscle. The musculo-tendinous insertions of the sterno-mastoid and splenius capitis muscles are divided, and branches of the posterior auricular and occipital arteries may need ligation. The exposure is illustrated in Fig. 2.

The bone overlying the antrum is exenterated and the antrum opened. The postero-superior osseous canal wall is thinned, and the short process of the incus visualized. A gutter is then cut to the mastoid tip and the cells in this region removed, as this area is later filled with medical grade elastomer (Silastic: Dow Corning) to allow the receiver-stimulator unit to fit snugly into place. All air cells in this region should be removed as their drainage could be obstructed by the Silastic insert. The removal of mastoid cells is then extended medially and posteriorly over the sigmoid sinus. Delineation of the lateral extent of the sinus at this stage is helpful as its position is one of the main constraints against sinking the hearing prosthesis 


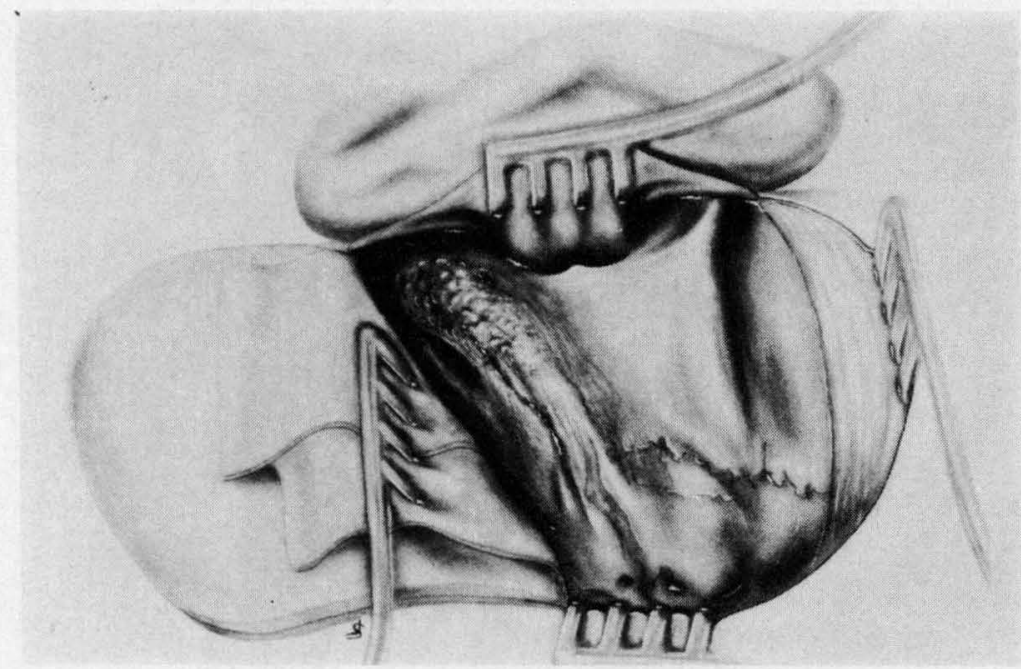

FIG. 2

A drawing of the cochlear implant operation showing the elevation of the skin and fascial flaps, and exposure of the mastoid bone.

well down in the bone. The removal of cells is then continued to the tegmen and the cells in this area together with those in the sinodural angle are removed with care to avoid exposing the dura. It is considered important to do this as the implantation of a foreign body adds to the likelihood of infection, and it is therefore considered desirable not to open up potential pathways for infection to the brain and its coverings.

A posterior tympanotomy is performed as described by Sheehy (1970), and the round window exposed. A bed for the unit is then cut in the mastoid bone. In cutting this bed the supra-mastoid crest is a useful guide to the direction of the upper boundary, and the bone needs to be drilled as close as possible to the middle fossa dura without exposing it. Pre-operative $\mathrm{x}$-rays are useful in this respect in determining whether there is a low lying dura, and this can be a factor in selecting the side for operation. The bed is made as deep as possible and a limit is usually set by the position of the sigmoid sinus. The bed created is illustrated in Fig. 3. An exact replica of the receiver-stimulator unit is then used to check that the bed has been made the correct size. Following haemostasis a mould is made from Silastic in order to support the unit anteriorly; otherwise, it would rock and the anterior end would tend to fall inwards. The Silastic mould also helps to cushion any bumps received by the package.

The next step in the surgery is to insert the electrode bundle around the scala tympani so that the electrodes will lie as close as possible to residual auditory nerve fibres in the speech frequency range. As an electrode array has been designed to do this by insertion through the round window (Clark et al., in press), this is the normal approach. There are, however, 


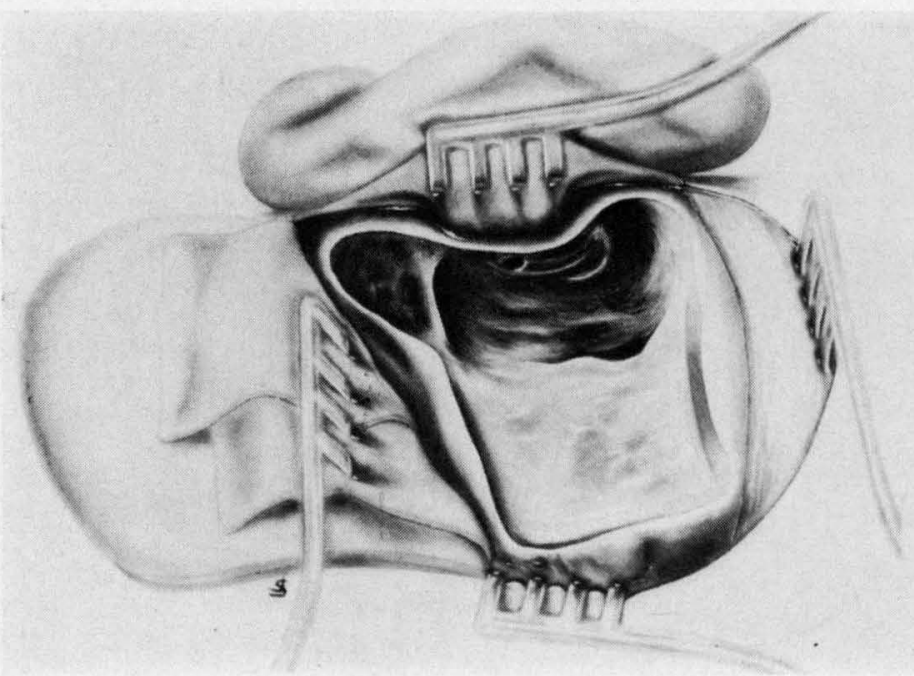

FIG. 3

A drawing of the cochlear implant operation showing the bed created in the mastoid bone for the hearing prosthesis unit.

some patients with a profound or total hearing loss in whom the basal turn of the cochlea is narrowed or obliterated. Usually this is due to localized labyrinthitis ossificans following bacterial labyrinthitis. In these patients it is considered preferable to insert the electrode array via the apical turn approach (Clark et al., 1975). An indication that the basal turn of the cochlea is reduced in size may be obtained from antero-posterior polytomes of the temporal bone. It is our practice, however, to insert a dummy Silastic probe through the round window to determine how far an electrode array should pass. If this indicates that it can be inserted a satisfactory distance, this is then carried out. Otherwise an apical turn insertion would be undertaken.

The round window electrode insertion is carried out as gently as possible through a posterior tympanotomy, and it is facilitated with a micro-claw and forceps coated in Silastic. The flexibility of the electrode array also enables it to be inserted through the round window via an anterior tympanotomy approach to the middle ear, using micro-claws and forceps coated in Silastic. Anatomical studies have shown, however, that the electrode may be inserted an extra few millimetres along the cochlea using the posterior tympanotomy approach, and it is preferred for this reason. With an apical turn insertion angled and straight claws are invaluable for manipulating the electrode array in a direction which is coaxial with the cochlear turn, and this is best done by an anterior tympanotomy approach. The gripping capacity of the micro-claw can be further improved by making it hollow and applying suction. A magnified view of the micro-claws can be seen in Fig. 4. The electrode is inserted as 


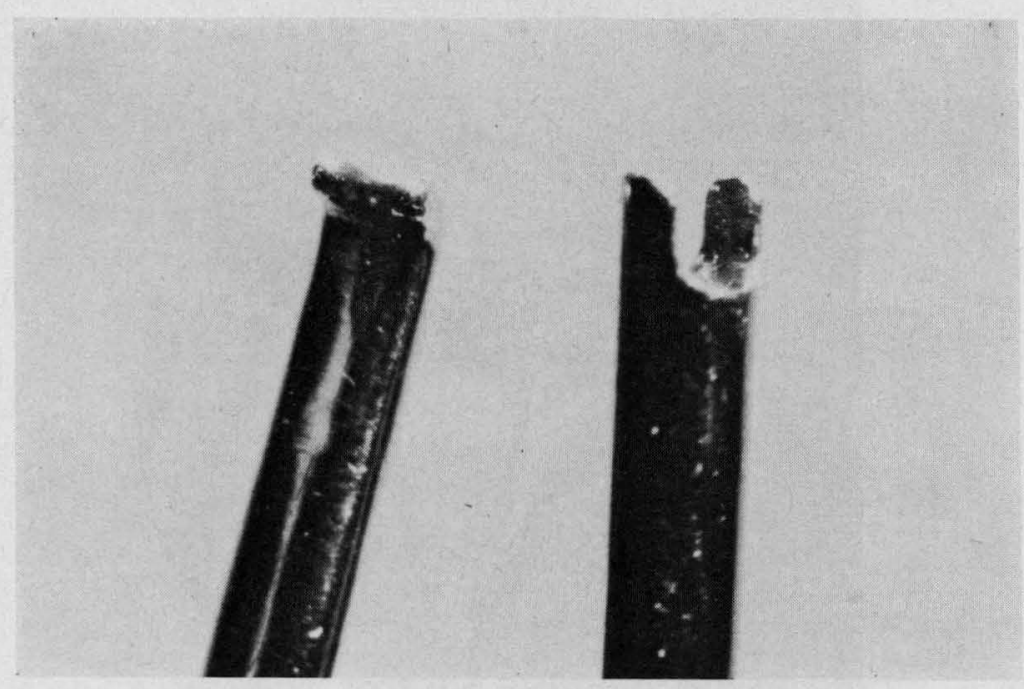

FIG. 4

A magnified view of the straight and angled micro-claws used for inserting an electrode array into the cochlea through the round window or an opening drilled into the apical turn.

far as possible with a small Silastic foam collar adhering to the electrode at a point where it will fit into the round window niche. This will result in fibrous tissue growing into the sponge which will reduce the chance of infection entering the inner ear from the middle ear. The Silastic mould and cochlear implant unit are then eased into place (Fig. 5). During this procedure the electrode bundle lying outside the cochlea is tucked into the depths of the mastoid cavity. The total length of the electrode bundle is $7 \mathrm{~cm}$, as additional length is needed in case the package needs to be replaced, when the device can be lifted from its bed and worked on without disturbing the intra-cochlear electrode.

After ensuring haemostasis the two fascial flaps are sutured together as illustrated in Fig. 6, using buried nylon sutures. It has been found convenient to use the more superficial flap to cover the posterior aspect of the device, and stitch it to periosteum. The deeper flap covers the anterior aspect of the device, and is stitched to the fascia along the posterior part of the auditory canal. The superior part of the device will still need to be covered, and this can be achieved by swinging a flap of temporalis fascia down and suturing this to the inferiorly-based flaps as illustrated in Fig. 6.

The wound is then irrigated with a dilute solution of the antibiotics being used parenterally, and closed in layers with interrupted chromic catgut sutures for the subcutaneous tissues, and black silk for the skin. The post-operative result two weeks following surgery is shown in Fig. 7.

The operation described leads to the placement of the receiving coil just behind the upper half of the pinna, and as illustrated in Fig. 8 this is a convenient location for the application of the transmitter coil. 


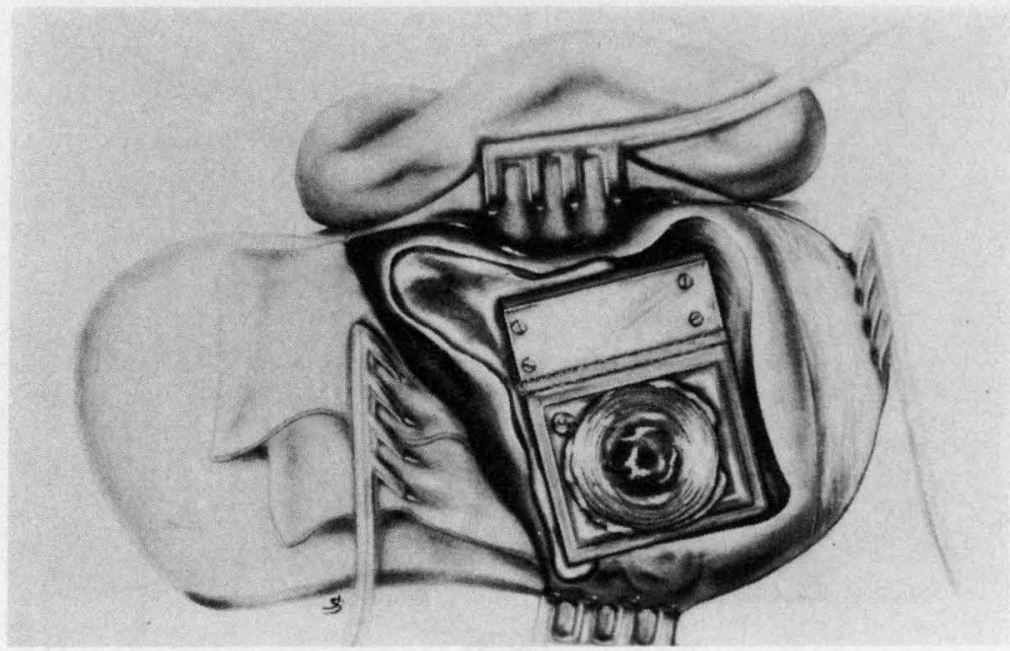

FIG. 5

A drawing of the cochlear implant operation showing the Silastic mould and cochlear implant unit placed in the bed created in the mastoid part of the temporal bone.

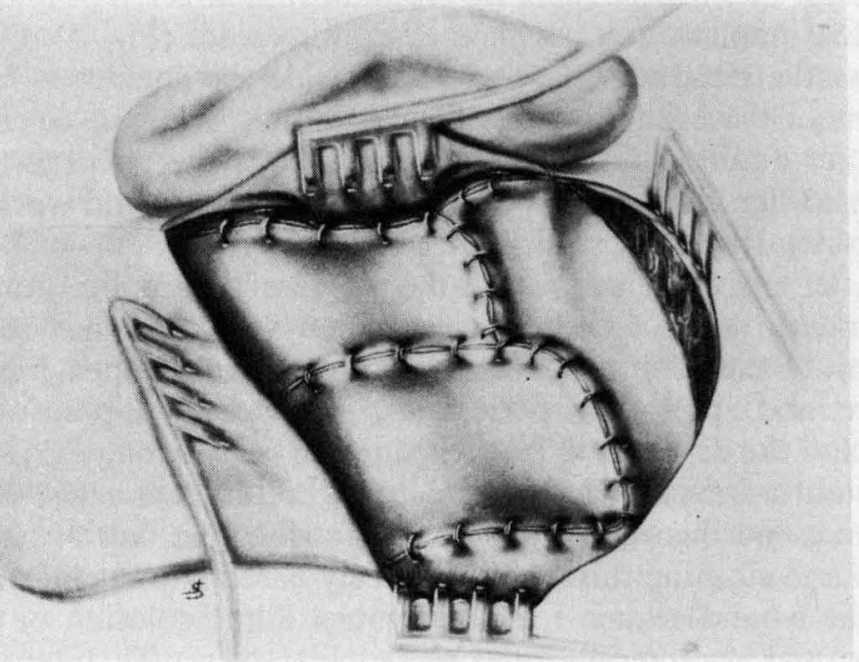

FIG. 6

A drawing of the cochlear implant operation showing the superficial, deep and temporal fascial flaps sutured over the cochlear implant unit. 


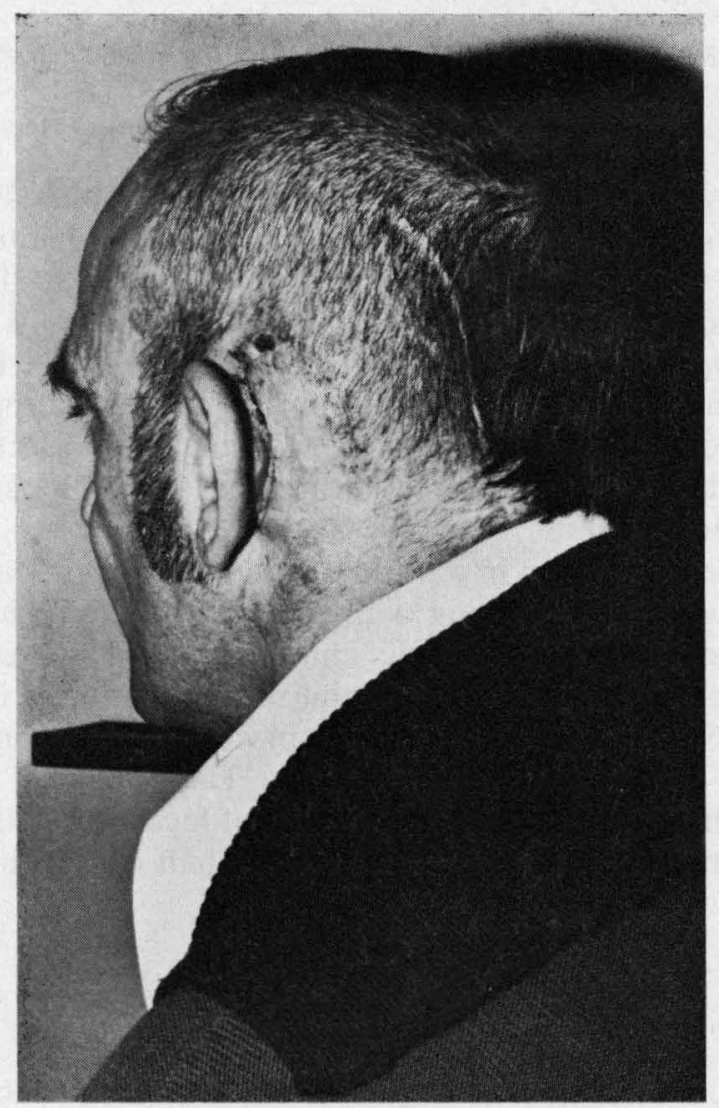

FIG. 7

A photograph of the patient's wound two weeks post-operatively.

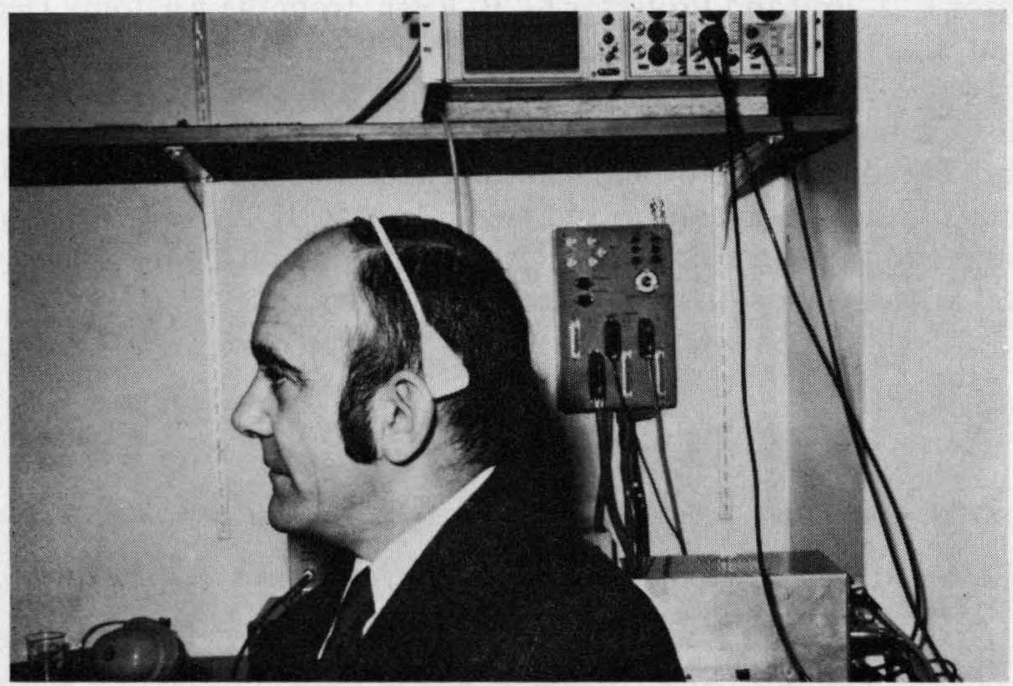

FIG. 8

A photograph of the patient showing the position of the transmitter coil where it overlies the implant receiving coil. 


\section{Summary}

The surgery for a multiple-electrode cochlear implantation has been described. This involves inserting the electrode array into the cochlea either through the round window or an opening drilled in the apical turn. The introduction of the electrode array into the cochlea is facilitated by specially-designed micro-claws and forceps. It is also made easier through a posterior tympanotomy, but an anterior tympanotomy approach can be used. A small collar of Silastic sponge, adhering to the electrode, fits into the round window niche to reduce the chance of infection passing from the middle to the inner ear.

There is adequate room in a normal adult mastoid to seat the cochlear implant unit without producing a noticeable swelling. This is done by performing a cortical mastoidectomy and cutting a bed in the mastoid part of the temporal bone. The unit is stabilized by seating it in a mould of medical grade Silastic. It is maintained in place with flaps constructed from subcutaneous, deep and temporalis fascia. The operation results in the placement of the receiving coil at a convenient location for the application of the transmitting coil just behind the upper half of the pinna.

\section{Acknowledgements}

We would like to acknowledge the financial help provided by the Channel O Nerve Deafness Appeal, and the National Health and Medical Research Council of Australia. We wish to thank Professor K. G. Bradley, Professor L. J. Ray and Professor G. B. Ryan, from the Anatomy Department at the University of Melbourne, for facilities and material. We acknowledge the helpful discussions with our colleages, Mr. R. C. Black, Mr. I. C. Forster, Dr. K. J. Kane and Mr. J. Patrick. We would like to thank the Medical Director and staff of The Royal Victorian Eye and Ear Hospital for their co-operation and help; also Mr. R. J. Walkerden for his assistance, Miss Maree Bradbury for the photography, Mr. J. Salter for medical artwork and Miss J. Maher for the typing.

\section{REFERENCES}

ClaRK, G. M., Hallworth, R. J., and ZDANIUS, K. (1975) Journal of Laryngology and Otology, 89, 787.

Clark, G. M., Black, R., Dewhurst, D. J., Forster, I. C., Patrick, J. K., and Tong, Y. C. (1977) Medical Progress through Technology, 5, 127.

Clark, G. M., Tong, Y. C., Black, R., Forster, I. C., Patrick, J. F., and Dewhurst, D. J. (1977) Journal of Laryngology and Otology, 91, 935.

Clark, G. M., Black, R., Forster, I. C., Patrick, J. F., and Tong, Y. C. (1978) Journal Acoustical Society of America, 63, 631.

ClaRK, G. M., PATRICK, J. F., and BAILEY, Q. (In press) Journal of Laryngology and Otology. 
PATRICK, J. F. (1977) Research Report, Department of Otolaryngology, University of Melbourne.

SHEEHY, J. L. (1970) Journal of Laryngology and Otology, 84, 1.

Department of Otolaryngology,

University of Melbourne,

Parkville 3052,

Victoria, Australia. 


\section{University Library}

\section{- M M N E R VA A gateway to Melbourne's research publications}

Minerva Access is the Institutional Repository of The University of Melbourne

Author/s:

Clark, Graeme M.;Pyman, Brian C.;Bailey, Quentin R.

Title:

The surgery for multiple-electrode cochlear implantations

Date:

1979

Citation:

Clark, G. M., Pyman, B. C., \& Bailey, Q. R. (1979). The surgery for multiple-electrode cochlear implantations. Journal of Laryngology and Otology, 93(3), 215-223.

Persistent Link:

http://hdl.handle.net/11343/28718 